\title{
Environmentally benign Fe(III)- montmorillonite for rapid adsorption of methylene blue dye in aqueous medium under ambient conditions
}

\author{
M. Vinuth ${ }^{1}$, H. S. Bhojya Naik ${ }^{1 *}$, M. M. Mahadevaswamy ${ }^{2}$ and M. C. Prabhakara ${ }^{3}$
}

${ }^{*}$ Correspondence:

hsb_naik@rediffmail.com

${ }^{1}$ Department of Industrial

Chemistry, Kuvempu

University, Shankaraghatta,

Shimoga 577 451, India

Full list of author information

is available at the end of the

article

\begin{abstract}
Herein we have explored the highly efficient and environmentally benign clay mineral, $\mathrm{Fe}(\mathrm{III})$-montmorillonite [Fe(III)-Mt], for adsorption of methylene blue (MB) dye from aqueous solution under ambient conditions. The Fe(III)-Mt was interacted with MB dye solution at different $\mathrm{pH}$, temperature and solid-to-liquid ratio. The concentration of MB dye removal was estimated from its optical density at $\lambda_{\max }=665 \mathrm{~nm}$ using UV-Vis spectrophotometer. The MB dye removal was rapid at basic $\mathrm{pH}$ and increases with temperature up to $40^{\circ} \mathrm{C}$. A complete reduction (100\%) was occurred in about $7 \mathrm{~min}$ at $\mathrm{pH} 7$ and 10 while at $\mathrm{pH} 3$ in about 10 min. The time taken for complete reduction at 0,30 and $40^{\circ} \mathrm{C}$ are 10,7 and 5 min respectively. The removal followed by adsorption of dye molecules on the spent clay mineral was evident from FESEM/EDX analysis. More importantly, Fe(III)-Mt could be separated and retrieved easily after the reaction by centrifugation from the degraded $\mathrm{MB}$ dye solution. The experimental results of $\mathrm{MB}$ dye removal from Fe(III)-Mt follows the pseudo first order kinetics. This study reveals that Fe(III)-Mt has the potential to be used as reductant/adsorbant to remove cationic pollutants effectively and rapidly from drinking water and large scale of industrial wastewater.
\end{abstract}

Keywords: Fe(III)-montmorillonite, Methylene blue, Remediation, Adsorption

\section{Introduction}

The main difficulties associated with the treatment of textile wastewater are the removal of dye effluents which possess complex aromatic structures make them more stable and hence it is difficult to remove the effluents discharged into water reservoirs. Moreover these effluents causes water pollution in large scale become serious environmental issue in recent years (Mahlambi et al. 2015).

Methylene blue (MB) is a cationic thiazine dyes whose molecular structure as shown in Fig. 1a. This is a heterocyclic aromatic chemical compound with the molecular formula $\mathrm{C}_{16} \mathrm{H}_{18} \mathrm{~N}_{3} \mathrm{SCl}$, while it appears as a solid, odorless and dark green powder that gives a blue colour when dissolved in water. It is used in wide variety of applications such as colouring paper, temporary hair colourant, dyeing cottons, wools and coating for paper stock (Yao et al. 2010). Furthermore, it is used in cosmetics, food, leather, plastic, paper, 


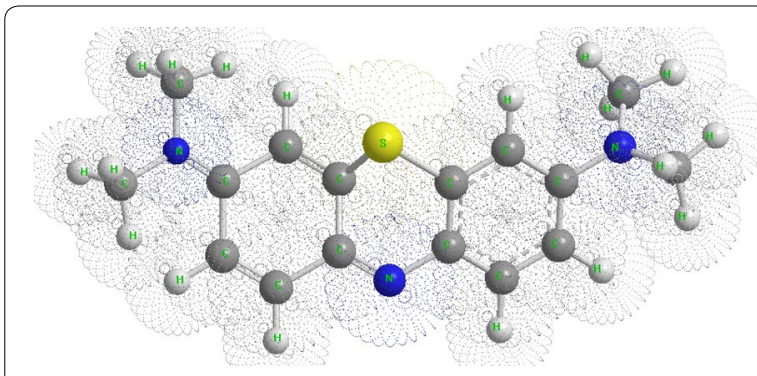

a

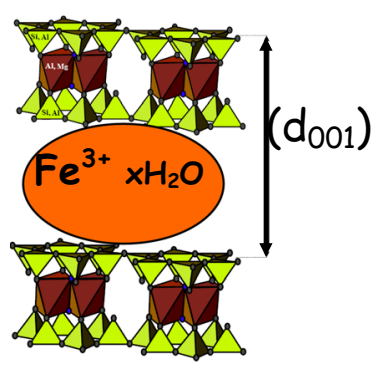

b

Fig. 1 a Molecular structure of MB dye. b Schematic representation of Fe(III)-Mt clay mineral

textile and pharmaceutical industries (Vinothkannan et al. 2015). Although MB dye is not extremely hazardous, it can cause various toxic effects such as eye burns, irritation to skin and the gastro-intestinal tract (He et al. 2013). Acute exposure to MB could cause difficulty in breathing, nausea, vomiting, profuse sweating and mental confusion (Rafatullah et al. 2010). Therefore, it is essential to treat the MB dyestuffs wastewater before being released into water reservoirs and the environment.

Existing strategies like coagulation, chemical oxidation, adsorption, electrochemical and biological degradation focus on the removal and degradation of organic contaminants from effluents (Dutta et al. 2001; Shannon et al. 2008; Schwarzenbach et al. 2006; Zhang et al. 2012). Moreover, many research groups have been developed various methods like active carbon adsorption, dissolved air flotation, biochemical, chemical and microorganisms mediated reductions to degrade the MB dye. However these techniques are considered to be ineffective due to the phase transfer of pollutants, difficulty in removal of microorganisms from the degraded dye molecules and extreme resistive character of the dyes to microorganisms (Vinothkannan et al. 2015). These methods are still persisting as a major challenge in large scale field applications. Lv et al. (2012) synthesized the $\mathrm{ZnO}$-reduced graphene oxide (RGO)-carbon nanotube (CNT) composites via microwave-assisted reaction and investigated their photocatalytic performance in MB dye degradation process. As a consequence, $\mathrm{ZnO}-\mathrm{RGO}$ showed $88 \%$ degradation efficiency under increased light absorption.

He et al. was investigated the batch adsorption of $\mathrm{MB}$ dye onto nanocrystalline cellulose $(\mathrm{NCC})$ at different $\mathrm{pH}$ and temperature and found that carbon monolith $(\mathrm{CM})$ showed 94\% desorption efficiency of MB dye within 10 min (He et al. 2013). Furthermore, it has been inferred that polyacrylamide grafted xanthan gum and its nanosilica composite ( $\mathrm{h}-\mathrm{XG} / \mathrm{SiO}_{2}$ ) through a sol-gel method as adsorbents to remove both $\mathrm{MB}$ and MV dyes (methyl violet) from aqueous solution, the results showed $99.4 \%$ removal efficiency (Ghorai et al. 2014). $\mathrm{Fe}_{3} \mathrm{O}_{4} @ P$ Polydopamine-Ag core-shell microspheres were used as an adsorbent for removal of $\mathrm{MB}$ dye, but these microspheres showed excellent reduction capabilities on $\mathrm{MB}$ dye only in the presence of $\mathrm{NaBH}_{4}$ (Xie et al. 2014). $\mathrm{PrPO}_{4}$ nanorods-reduced graphene oxide composites in comparison with bare $\mathrm{PrPO}_{4}$ nanorods are used as photocatalysts for degradation of $\mathrm{MB}$ dye and showed good photocatalytic activity only in the presence of simulated sunlight irradiation (Lv et al. 2014). Although these heterogeneous reductants/adsorbents are used for the degradation and adsorption 
processes, there will be an incomplete reduction and time consumption is more. These are effective only in the presence of co-catalysts and sunlight irradiation. As a consequence, a keen focus has been given on the utilization of various clay minerals such as silica, alumina, and zeolites which selectively adsorb the toxic pollutants present in the water through adsorption/degradation process.

Clays are important class of materials that are readily available in nature. These are used as very good adsorbents, decolouration agents, ion exchangers, molecular sieves, catalysts (Kloprogge 1998). More importantly, clay minerals have attracted significant attention for diversified applications including pollutants removal/remediation, because of their high specific surface area, adsorption capacity and excellent adsorption behavior towards cationic sensitizers. These play a pivotal role as it supports various sensitizers because of their large surface area and easy adsorption of cationic sensitizers (Cenens and Schoonheydt 1988). The most used clays as nano-adsorbents are montmorillonite/ smectite group and kaolinite group clays (Liu and Zhang 2007). Cu(II)-exchanged montmorillonite (Ma et al. 2004) and $\mathrm{TiO}_{2}$ pillared montmorillonites (Chen et al. 2014) are successfully employed for the adsorption and degradation of MB dye.

Montmorillonite (Mt) is 2:1 dioctahedral smectite group clay mineral having required qualities such as low diffusion, high absorption capacity, low hydraulic conductivity and layered structure. The octahedral alumina sheet is sandwiched between tetrahedral silicate sheets. The negative charge is created on the clay mineral due to the isomorphic substitution in the octahedral sites (by $\mathrm{Mg}, \mathrm{Fe}$, and $\mathrm{Ti}$ ) and tetrahedral sites (by $\mathrm{Al}, \mathrm{Fe}$ ). Such a permanent negative layer charge is balanced by exchangeable cations like $\mathrm{Ca}^{2+}, \mathrm{Na}^{+}$etc. at the interlayer. i.e., the redox sensitive $\mathrm{Fe}(\mathrm{III})$ ions are placed in the interlayer of clay mineral becomes Fe(III)-Mt as shown in Fig. 1b. Thus, the cation exchange capacity (CEC) of clay mineral depends on the net elemental composition that varies with the geographical availability in the environment (Stucki 2006). The properties and uses of this clay mineral can be modified not only by altering the structural $\mathrm{Fe}(\mathrm{II}) / \mathrm{Fe}(\mathrm{III})$ ratio (Grygar et al. 2007), but also by replacing the interlayer cations with a variety of inorganic and organic cations (Leungo et al. 2011; Bigi et al. 2000). Environmentally benign and redox sensitive metal ions like ferrous and ferric ions in the interlayer of smectite clay mineral can impart many technological important properties. It is obvious that the development of new method which involves heterogeneous reaction would be suitable for large-scale synthesis. Fe-pillared montmorillonite or $\mathrm{Fe}(\mathrm{III})$ incorporated clay minerals has been extensively used in heterogeneous catalytic systems and were proved to be advantageous in both economic and environmental point of view (Vinoda and Manjanna 2014; Brigatti et al. 2000).

There are only a few reports on natural (Parthasarathy et al. 2003; Shi et al. 2011) and modified clay minerals (Manjanna et al. 2009; Wu et al. 2012; Vinuth et al. 2015) for $\mathrm{Cr}(\mathrm{VI})$ reduction. The availability as well as the amount or access of $\mathrm{Fe}(\mathrm{III})$ ions for dye degradation was very limited. Hence it is important to make use of Fe(III)-Mt, i.e., the redox sensitive $\mathrm{Fe}(\mathrm{III})$ ions are placed in the interlayer of clay mineral to augment the real field applications. Recently, Manjanna et al. (2009) has reported the preparation of $\mathrm{Fe}(\mathrm{III})-\mathrm{Mt}$ and explained the basic properties along with stability. Hence, it is possible to make use of such an important redox sensitive clay mineral for the adsorption of $\mathrm{MB}$ dye. 
The main objective of the present study is the application of Fe(III)-Mt as an effective reductant for $\mathrm{MB}$ dye removal in aqueous solution. The reduction reaction was carried out at different $\mathrm{pH}$ and temperature by varying the amount of Fe(III)-Mt. However, to till date, the use of Fe clay minerals as a reductant/adsorbent for the adsorption of dyes was limited. Hence facile and reliable preparation of Fe(III)-Mt clay mineral is having excellent adsorption and degradation properties make a suitable reductant for removal of $\mathrm{MB}$ dye from aqueous solution.

\section{Methods}

\section{Materials}

Kunipia F montmorillonite was used for whole experiments which contain $>98 \%$ of $\mathrm{Na}$-montmorillonite and the only impurity was quartz. The composition of raw montmorillonite clay mineral is given as $\left(\mathrm{Na}_{0 \cdot 431} \mathrm{~K}_{0 \cdot 002} \mathrm{Ca}_{0 \cdot 002}\right)\left(\mathrm{Al}_{1 \cdot 56} \mathrm{Mg}_{0.305} \mathrm{Fe}_{0 \cdot 099} \mathrm{Ti}_{0 \cdot 007}\right)^{\text {oct }}$ $\left(\mathrm{Si}_{3 \cdot 949} \mathrm{Al}_{0 \cdot 051}\right)^{\text {tet }} \mathrm{O}_{10}(\mathrm{OH})_{2} \mathrm{nH}_{2} \mathrm{O}$ with a CEC of about $1.2 \mathrm{meq} / \mathrm{g}$ (Manjanna et al. 2009). The dye with a labelled purity of more than $99 \%$ was obtained from s. d. fine-chem limited, India and used as such. Double distilled water was used throughout in this study. The percentage of dye removal from aqueous solution was estimated from its optical density at $\lambda_{\max }=665 \mathrm{~nm}$ using UV-Vis spectrophotometer.

\section{Fe(III)-Mt preparation}

The raw clay mineral (10 g in $1 \mathrm{~L}$ ) was stirred with $0.4 \mathrm{M} \mathrm{FeCl}_{3}$ solution up to $24 \mathrm{~h}$ in terms of solid to liquid ratio to convert the clay into Fe(III)-Mt. This process was repeated thrice to get the complete conversion of clay to Fe(III)-Mt. After cation exchange, the clay mineral was washed with distilled water by centrifugation and then followed by filtration using $0.2 \mu \mathrm{m}$ filter, until no chloride was detected while washings by $\mathrm{AgNO}_{3}$ test. Later, solid sample was dried at room temp $\left(\mathrm{RT} \sim 25^{\circ} \mathrm{C}\right)$, ground to powder form and stored in a vacuum desiccator.

In order to estimate the interlayer iron, Fe(III)-Mt was subjected for cation exchange with $0.05 \mathrm{M} \mathrm{H}_{2} \mathrm{SO}_{4}$ for about $24 \mathrm{~h}$. The ratio of ferrous to ferric ions $\left(\mathrm{Fe}^{2+} / \mathrm{Fe}_{\text {total }}\right.$ where $\mathrm{Fe}_{\text {total }}=\mathrm{Fe}^{2+}+\mathrm{Fe}^{3+}$ ) released was determined by 1,10 phenanthroline method (Brigatti et al. 2000) using UV-Vis spectrophotometer $\left(\lambda_{\max }=510 \mathrm{~nm}\right)$.

The X-ray diffraction patterns (XRD) of the samples were recorded using D2 phaser XRD (Bruker AXS GmbH, Germany) with Ni-filtered $\mathrm{Cu} \mathrm{K}_{\alpha}$ radiation, $\lambda=1.5417 \mathrm{~nm}$. Infrared spectrum of the samples was recorded by $\mathrm{KBr}$ pellet method using IR analyzer (FT-IR8600PC, Shimadzu Corporation, Japan). The micrographs of freshly prepared and spent Fe(III)-Mt was recorded using field emission scanning electron microscope (Nova NanoSEM 600, FEI Company, Netherlands) along with energy dispersive X-ray (EDX) analysis for approximate elemental composition.

\section{Removal of MB dye by Fe(III)-Mt from aqueous solution}

In a typical stoichiometric case, freshly prepared Fe(III)-Mt (0.03 g) was added to MB dye solution $(0.025 \mathrm{mM}, 100 \mathrm{~mL})$ and stirred magnetically. The reaction was also carried out at different solid-to-liquid ratio, $\mathrm{pH}$ 3-10 (adjusted with dil. $\mathrm{HCl}$ and $\mathrm{NaOH}$ ) and temperature 0,30 and $40{ }^{\circ} \mathrm{C}$. The reaction mixture was withdrawn periodically by using a syringe tube and then centrifuges (REMI, R-8C BL BENCH TOP CENTRIFUGE) to 
separate the suspended clay particles. The decrease in the dye concentration was estimated from its optical density. The decrease in the dye concentration due to reaction between $\mathrm{Fe}(\mathrm{III})-\mathrm{Mt}$ and $\mathrm{MB}$ dye was expressed in terms of \% reduction as a function of time. The spent $\mathrm{Fe}(\mathrm{III})-\mathrm{Mt}$ was separated by centrifugation, washed thoroughly with water and vacuum dried at room temperature for further characterization using X-ray diffraction (XRD), Fourier transform infrared spectroscopy (FT-IR) and field emission scanning electron microscope with energy dispersive X-ray analysis (FESEM/EDXA) techniques.

\section{Results and discussion}

\section{Formation of Fe(III)-Mt}

The concentration of iron has been obtained from $0.5 \mathrm{~g}$ of Fe(III)-Mt using different reagents $\left(100 \mathrm{~mL}\right.$ ) viz., $0.05 \mathrm{M} \mathrm{H}_{2} \mathrm{SO}_{4}, 0.5 \mathrm{M}(\mathrm{NH})_{4} \mathrm{C}_{2} \mathrm{O}_{4}, 1 \mathrm{M} \mathrm{NaCl}, 0.05 \mathrm{M} \mathrm{Na}_{2}$ EDTA. The total $\mathrm{Fe}(\mathrm{III})$ ions extracted was about $1.18 \mathrm{meq} / \mathrm{g}$. In addition, X-ray diffraction (XRD), Fourier transform infrared spectroscopy (FT-IR) and Field emission scanning electron microscope with energy dispersive X-ray analysis (FESEM/EDXA) results confirmed the formation of $\mathrm{Fe}(\mathrm{III})-\mathrm{Mt}$.

The X-ray diffraction (XRD) patterns of $\mathrm{Fe}(\mathrm{III})-\mathrm{Mt}$ in comparison with $\mathrm{Ca}(\mathrm{II})-\mathrm{Mt}$, $\mathrm{Na}(\mathrm{I})-\mathrm{Mt}$ and spent $\mathrm{Fe}(\mathrm{III})-\mathrm{Mt}$ at relative humidity (RH) $40 \%$ are shown in Fig. 2a. The basal spacing, $\mathrm{d}_{001}$, values are as follows: $\mathrm{Fe}(\mathrm{III})-\mathrm{Mt}, 15.3 \AA$; $\mathrm{Ca}(\mathrm{II})-\mathrm{Mt}, 14.9 \AA$ and $\mathrm{Na}-$ Mt, $12.1 \AA$. It is clear that the divalent cation exchanged clay minerals showed higher $\mathrm{d}_{001}$ value due to larger layer of hydration when compared to monovalent cation exchanged clay mineral. These values are in good agreement with the previously reported values (Manjanna et al. 2007; Kozai et al. 2001). In spent Fe(III)-Mt, basal spacing $d_{001}$ value

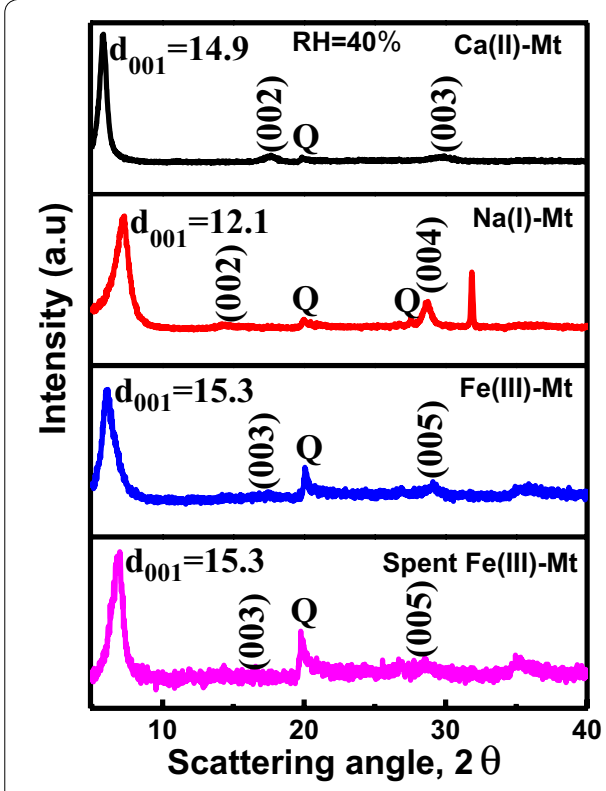

a

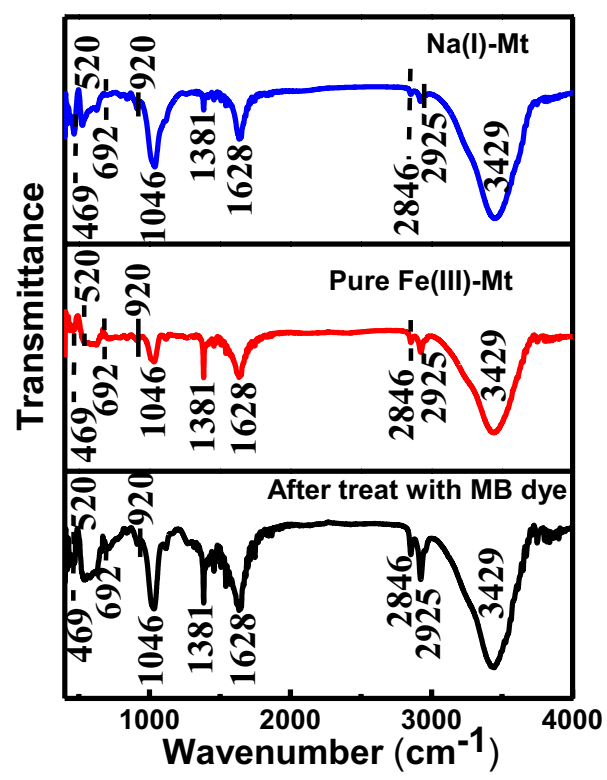

b

Fig. 2 a Powder XRD patterns of Fe(III)-Mt in comparison with $\mathrm{Ca}(\mathrm{II})-, \mathrm{Na}(\mathrm{I})-$, $\mathrm{Fe}(\mathrm{III})$ - and spent $\mathrm{Fe}(\mathrm{III})-\mathrm{Mt}$ at relative humidity $40 \%$. b FT-IR spectra of freshly prepared Fe(III)-Mt compared with $\mathrm{Na}$ (I)-Mt as well as spent $\mathrm{Fe}(\mathrm{III})-\mathrm{Mt}$ 
was almost same due to small amount of MB dye adsorbed on the surface area and hence it didn't show a significant peak using XRD analysis.

As shown in Fig. 2b, the Fourier transform infrared (FT-IR) spectra of freshly prepared $\mathrm{Fe}(\mathrm{II})-\mathrm{Mt}$ is similar to that of $\mathrm{Na}(\mathrm{I})-\mathrm{Mt}$. The basic structure of clay mineral has not undergone any significant changes. For instance, the bending vibration bands at $\sim 520 \mathrm{~cm}^{-1}$ for $\mathrm{Si}-\mathrm{O}-\mathrm{Al}$, and $920 \mathrm{~cm}^{-1}$ for $\mathrm{Al}_{2} \mathrm{OH}$ are intact. However stretching vibrations of Si-O group $\sim 1046 \mathrm{~cm}^{-1}$ are slightly broadened. The vibration bands at $1628 \mathrm{~cm}^{-1}$ corresponds to adsorbed water and $3429 \mathrm{~cm}^{-1}$ for water present at the interlayer. As revealed by Fourier transform infrared (FT-IR) spectra the spent clay mineral is intact in all respects when compared with pure Fe(III)-Mt.

\section{Effect of amount of $\mathrm{Fe}($ III)-Mt on MB dye removal from aqueous solution}

In order to determine the stoichiometric amount of $\mathrm{Fe}(\mathrm{III})-\mathrm{Mt}$, it was added to $\mathrm{MB}$ dye solution (MB solution $0.025 \mathrm{mM}, \mathrm{pH}$ 7) by varying the amount of Fe(III)-Mt from 0.01 to $0.03 \mathrm{~g}$. The concentration of MB dye removal was estimated from its optical density at $\lambda_{\max }=665 \mathrm{~nm}$ using UV-Vis spectrophotometer. The effect of amount $\mathrm{Fe}(\mathrm{III})-\mathrm{Mt}$ on the rate of adsorption of MB solution is depicted in Fig. 3. From the Fig. 3, it was observed that the required amount of $\mathrm{Fe}(\mathrm{III})-\mathrm{Mt}$ for $100 \%$ dye removal was $0.03 \mathrm{~g}$. It was observed that the rate increases with increase in Fe(III)-Mt from 0.01 to $0.03 \mathrm{~g}$.

\section{Effect of stoichiometry on MB dye removal from an aqueous solution}

Figure $4 \mathrm{a}-\mathrm{c}$ shows the $\%$ removal of $\mathrm{MB}$ dye at different $\mathrm{pH}$ as a function of time for different solid-to-liquid ratio viz., (a) $\mathrm{Fe}(\mathrm{III})-\mathrm{Mt}$ and MB dye are in stoichiometric amounts (0.03 g, $0.025 \mathrm{mM})$, (b) Fe(III)-Mt is stoichiometrically excess $(0.05 \mathrm{~g}, 0.025 \mathrm{mM})$ and (c) $\mathrm{Fe}(\mathrm{III})-\mathrm{Mt}$ is stoichiometrically less $(0.01 \mathrm{~g}, 0.025 \mathrm{mM})$. In general, the dye removal
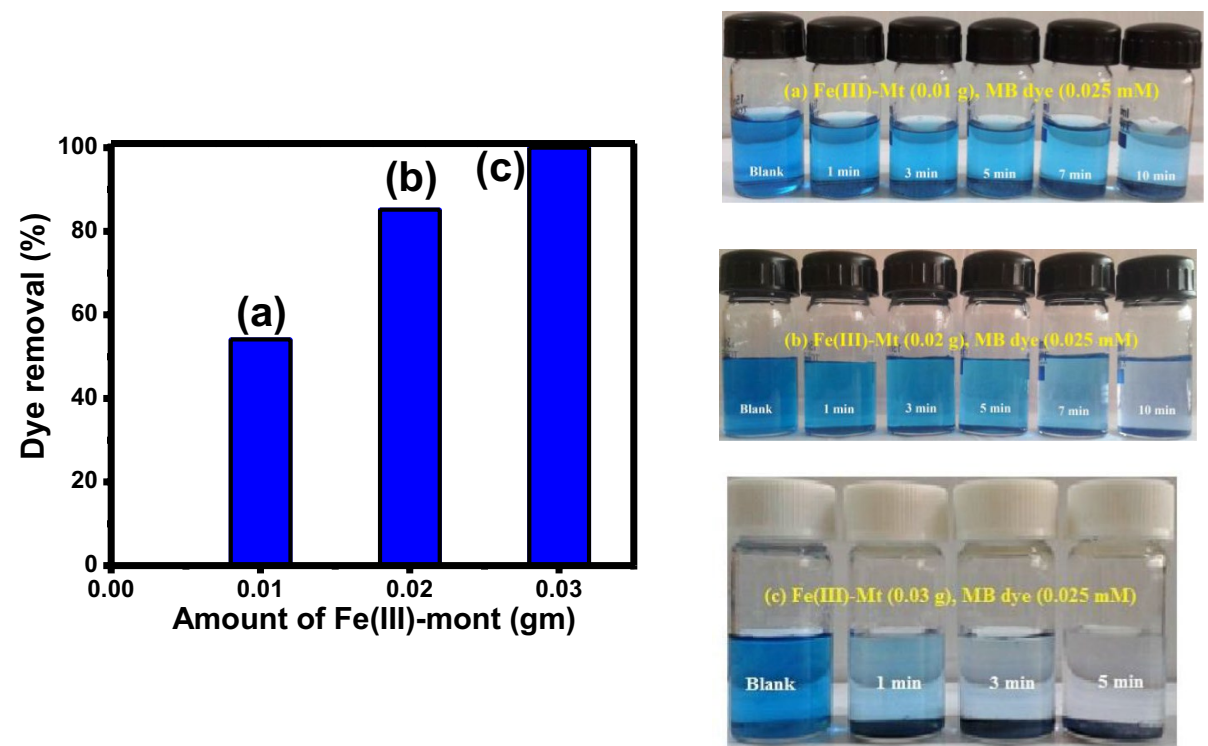

Fig. 3 Effect of amount Fe(III)-Mt on the rate of adsorption of MB dye solution; (a) Fe(III)-Mt (0.01 g), MB dye $(0.025 \mathrm{mM})($ b) Fe(III)-Mt (0.02 g), MB dye (0.025 mM) (c) Fe(III)-Mt (0.03 g), MB dye (0.025 mM) 


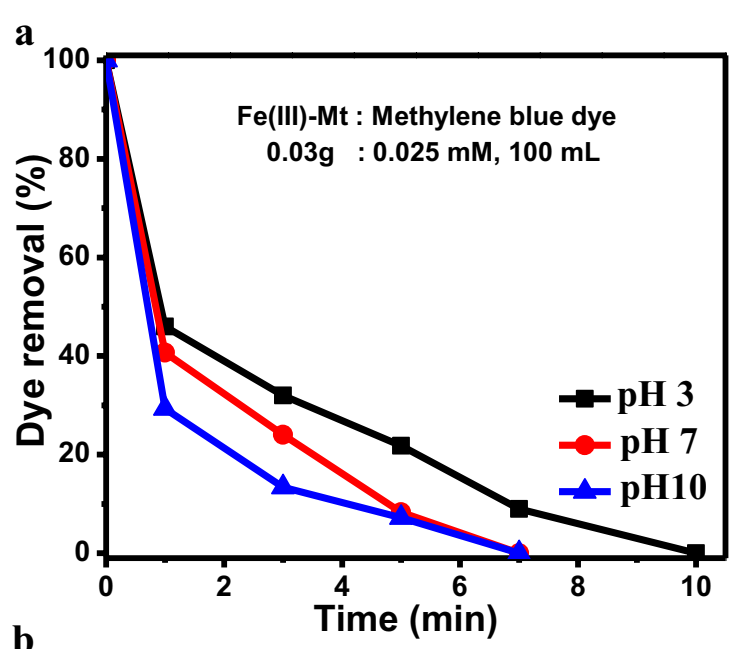

b
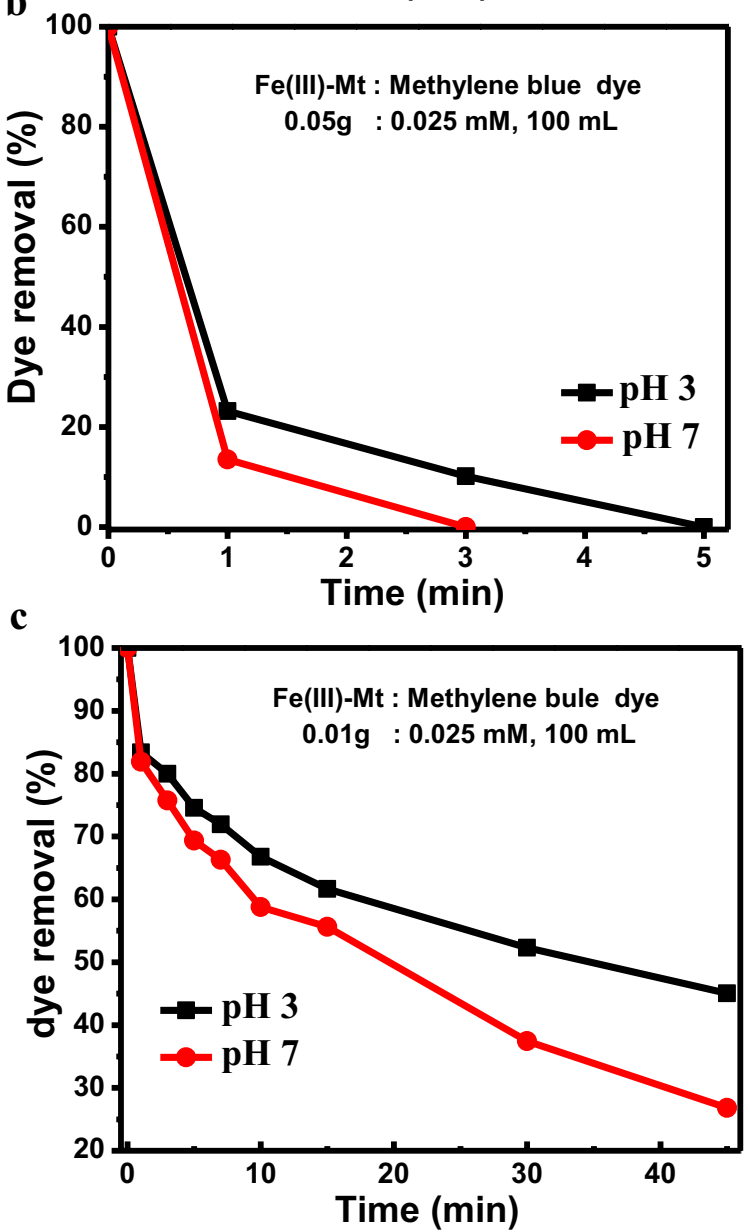

Fig. 4 Removal of MB dye by a stoichiometric amount of Fe(III)-Mt at different $\mathrm{pH}$. $\mathbf{b}$ Excess amount of $\mathrm{Fe}(\mathrm{III})-\mathrm{Mt}$ at $\mathrm{pH} 3$ and 7. c Sub-stoichiometric amount of Fe(III)-Mt at pH 3 and 7

by $\mathrm{Fe}(\mathrm{III})-\mathrm{Mt}$ is very rapid process. In each case, we saw a two-stage removal of $\mathrm{MB}$ dye by $\mathrm{Fe}(\mathrm{III})-\mathrm{Mt}$ : a rapid first stage followed by a slow second stage. A complete removal occurred in about $10 \mathrm{~min}$ at $\mathrm{pH} 3$ whereas at $\mathrm{pH} 7$ and 10 about $93 \%$ removal 
within 5 min and thereafter 100\% reduction occurred within 7 min when stoichiometric amount of $\mathrm{Fe}(\mathrm{III})-\mathrm{Mt}$ was present. From the literature, it was reported that the dye adsorption in acidic solution takes more time when compare to basic solution (Sohrabnezhad et al. 2009).

As shown in Fig. 4c, when stoichiometrically less amount of Fe(III)-Mt (0.01 g, $0.025 \mathrm{mM}$ ) was added, we observed a slow reduction around $35-40 \%$ removal at $\mathrm{pH} 3$ and $\mathrm{pH} 7$ at $10 \mathrm{~min}$. Reduction was faster and there after the removal efficiency gradually increased from 35 to $60 \%$ at pH 3 and $40-75 \%$ at pH 7 within 45 min. In both the cases (pH 3 and 7) complete removal was not attained due to the insufficient amount of $\mathrm{Fe}(\mathrm{III})-\mathrm{Mt}$.

It is well-known that the $\mathrm{pH}$ has a significant effect on the adsorption of dye. For instance, He et al. (2013) have demonstrated the application of powdered porous carbon monolith and nanocrystalline cellulose with high surface areas for the adsorption and desorption of $\mathrm{MB}$ dye. However the sorption capacity was high at basic $\mathrm{pH}(7-10)$ when compare to acidic $\mathrm{pH}(2-5)$. A similar observation was made by Ghorai et al. (2014) for the removal of $\mathrm{MB}$ and methyl violet (MV) dyes from aqueous solution using a nanocomposite of hydrolyzed polyacrylamide grafted xanthan gum and incorporated nanosilica. Meanwhile there was $65 \%$ adsorption of $\mathrm{MB}$ by h-XG/SiO $2-$ nanocomposite at $\mathrm{pH}$ $2-4$ whereas it was $80 \%$ at pH $4-6$ and $>95 \%$ at pH 7-10. Furthermore, Sohrabnezhad et al. (2009) has investigated the photocatalytic degradation of MB dye in aqueous solution using CoS/nanoAl-MCM-41 as a photocatalyst under visible light. The maximum degradation efficiency was observed in alkaline $\mathrm{pH} 8-10$ (>95\%) whereas in acidic $\mathrm{pH}$ $2-5$ only $60 \%$ degradation was observed with in a period of $30 \mathrm{~min}$.

Although these heterogeneous reductants/adsorbents are used for degradation and adsorption process, there will be an incomplete reduction and time consumption is more. These are effective only in the presence of co-catalysts and sunlight irradiation. However, in the present study we see the efficient removal of MB dye solution both in acidic as well as basic $\mathrm{pH}$.

\section{Effect of temperature on MB dye removal from an aqueous solution}

The reduction of $\mathrm{MB}$ dye by $\mathrm{Fe}(\mathrm{III})-\mathrm{Mt}$ was carried out in different temperatures $\left(0-40{ }^{\circ} \mathrm{C}\right)$ at $\left.\mathrm{pH} 7 \mathrm{in} \mathrm{Fig.} 5 \mathrm{a}-\mathrm{c}\right)$. In general, the \% dye removal increased with temperature up to $40{ }^{\circ} \mathrm{C}$. The time taken for complete reduction at 0,30 and $40{ }^{\circ} \mathrm{C}$ are 10,7 and $5 \mathrm{~min}$ respectively. Moreover when there was an excess of amount of Fe(III)-Mt (Fig. 5b), it took just $5 \mathrm{~min}, 3 \mathrm{~min}$ for the complete reduction of $\mathrm{MB}$ at 0 and $30{ }^{\circ} \mathrm{C}$ respectively. However, when $\mathrm{Fe}(\mathrm{III})-\mathrm{Mt}$ (Fig. 5c) was stoichiometrically less, the MB dye reduction was only 45 and $52 \%$ at 30 and $0{ }^{\circ} \mathrm{C}$ even after $1 \mathrm{~h}$. In both the cases complete adsorption is not attained due to the insufficient amount of Fe(III)-Mt.

He et al. (2013) have shown the temperature dependant adsorption and desorption of MB dye on porous carbon monoliths (CM) and nanocrystalline cellulose at 25 and $60{ }^{\circ} \mathrm{C}$. The adsorption capacity of $\mathrm{CM}$ slightly increased with the increase of temperature up to $60^{\circ} \mathrm{C}$. Chitosan/Fe-hydroxyapatite nanocomposite beads are used for removal of lead(II) ions and MB dye from aqueous solution. The results indicate that increasing the temperature leads to an increase in the adsorption of both metal and dyes (Samaneh et al. 2014). The usage of carbon nanotubes for the adsorption of MB dye from aqueous 

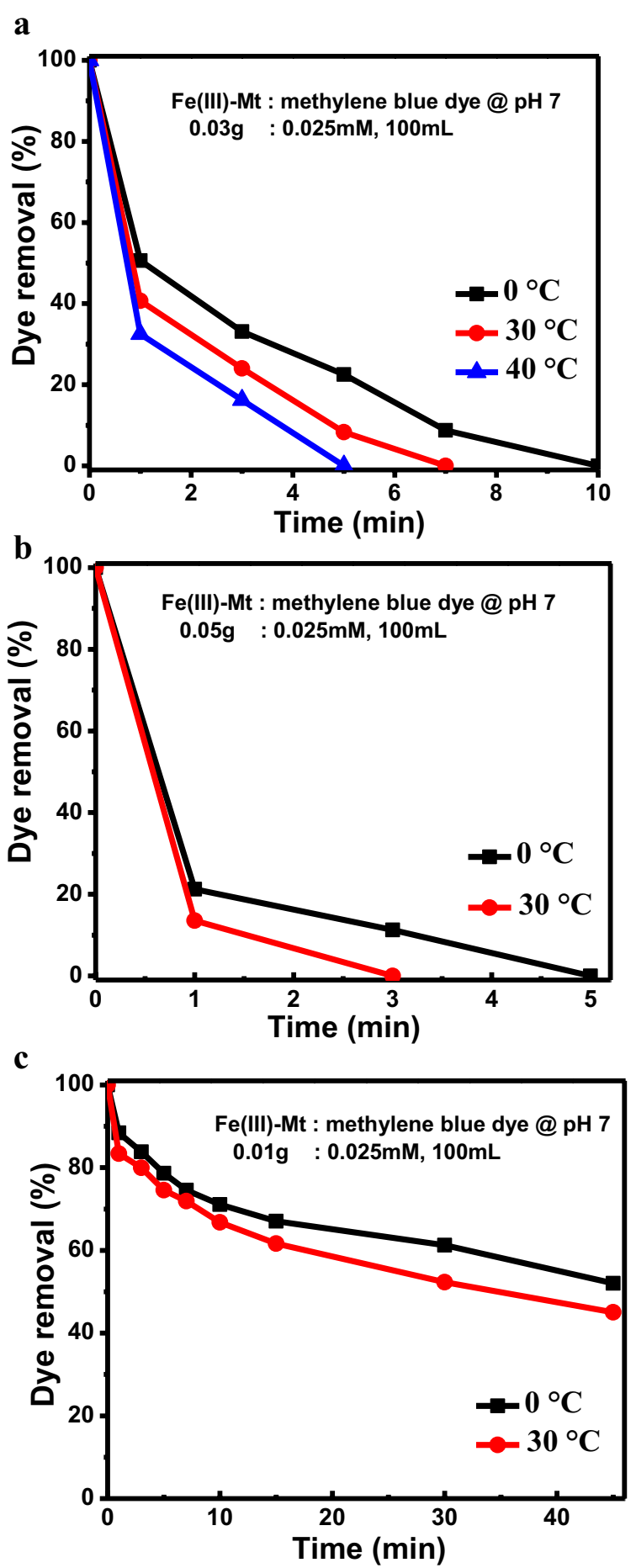

Fig. 5 Removal of $\mathrm{MB}$ dye by at $\mathrm{pH} 7$ by a stoichiometric amount of Fe(III)-Mt at different temperature. $\mathbf{b}$ Excess amount of $\mathrm{Fe}(\mathrm{III})-\mathrm{Mt}$ at $\mathrm{O}$ and $30^{\circ} \mathrm{C}$. c Sub-stoichiometric amount of $\mathrm{Fe}(\mathrm{III})-\mathrm{Mt}$ at 0 and $30^{\circ} \mathrm{C}$

solution was investigated by Yao et al. (2010). The experimental results have shown that the adsorption capacity increased with increasing temperature $(273-333 \mathrm{~K})$, but the removal of $\mathrm{MB}$ dye through adsorption on CNTs was found to be rapid at the initial 
period and then it became slow and stagnate with the increase in contact time. However, in the present study, we see the $100 \%$ removal of MB dye from $\mathrm{Fe}(\mathrm{III})-\mathrm{Mt}$ in all the temperatures ranging from 0 to $50^{\circ} \mathrm{C}$.

\section{Kinetics}

Rapid adsorption of MB dye was observed at $\lambda_{\max }=665 \mathrm{~nm}$. From the UV-Vis spectra it was observed that the absorbance of $\mathrm{MB}$ dye solution decreases with increasing time intervals which indicates that the dye is degraded rapidly due to the effect of $\mathrm{Fe}(\mathrm{III})-\mathrm{Mt}$. From the Fig. 6, it was obtained that plot of $2+\log$ O.D. with time was linear and MB dye removal from $\mathrm{Fe}(\mathrm{III})-\mathrm{Mt}$ follows the pseudo first order kinetics. The rate constant was determined using following expression $\mathrm{k}=2.303 \mathrm{X}$ Slope. By using this expression rate constant can be easily calculated.

Wang et al. (2014) reported the degradation of MB dye by ferrocene via heterogeneous fenton reaction. The experimental results indicated that the degradation of MB dye was found to follow the pseudo first order kinetics. Similarly, Ni/Ti layered double hydroxide is used as a photocatalyst for degradation of aqueous MB dye under visible light condition. The catalytic activity was found to be good under visible light condition and degradation reaction follows pseudo first order kinetics (Chowdhury and Bhattacharyya 2015).

\section{Examination of spent or oxidized Fe(III)-Mt}

In order to understand the removal and immobilization $\mathrm{MB}$ dye on the $\mathrm{Fe}(\mathrm{III})-\mathrm{Mt}$ clay mineral, it is important to examine the spent or oxidized Fe(III)-Mt. As revealed by Fourier transform infrared (FT-IR) spectra Fig. 2a, the spent clay mineral is intact in all aspects when compared to pure Fe(III)-Mt. Also, there is no indication about the presence of additional Fe-dye phase probably due to their small fraction. From the X-ray diffraction (XRD) analysis, we couldn't observe any significant peak in the spent $\mathrm{Fe}(\mathrm{III})$ Mt clay mineral. Moreover, in spent $\mathrm{Fe}(\mathrm{III})-\mathrm{Mt}$, basal spacing $\mathrm{d}_{001}$ value was almost the same due to small amount of MB dye adsorbed on the surface and it didn't show a significant peak from XRD analysis.

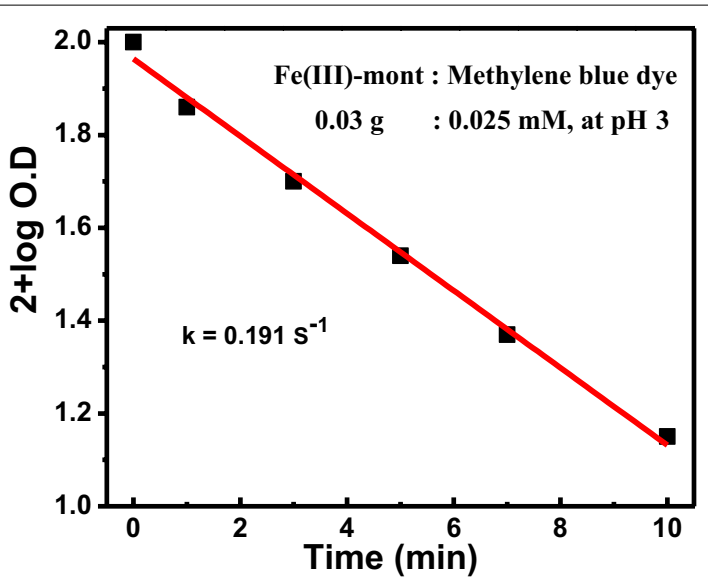

Fig. 6 Rapid removal of MB dye from Fe(III)-Mt follows the pseudo first order reaction 
Figure 7 represents the morphological images of $\mathrm{Fe}(\mathrm{III})-\mathrm{Mt}$ before and after treating with $\mathrm{MB}$ dye solution. In order to understand the reduction and it's adsorption on the clay mineral, it is important to examine the spent or oxidized Fe(III)-Mt for Field emission scanning electron microscope with energy dispersive X-ray (FESEM/EDXA) analysis. Accordingly, the Fe(III)-Mt was analyzed by FESEM/EDX spectra to observe any morphological changes upon dye adsorption. In Fig. 7b shows an appreciable change in the microstructure of Fe(III)-Mt. Moreover Energy dispersive X-ray (EDXA) analysis confirmed the adsorption of MB dye on the surface of spent Fe(III)-Mt as shown in Fig. 7b.

Figure 8 shows the photograph of a dry clay mineral before and after treating with $\mathrm{MB}$ dye in aqueous solution. From this figure we can observe a lot of changes in the spent clay mineral $\mathrm{Fe}(\mathrm{III})-\mathrm{Mt}$ and confirmed that $\mathrm{MB}$ dye was completely adsorbed on the Fe(III)-Mt, moreover dye was removed rapidly (100\%) within 5 min through adsorption process.

a
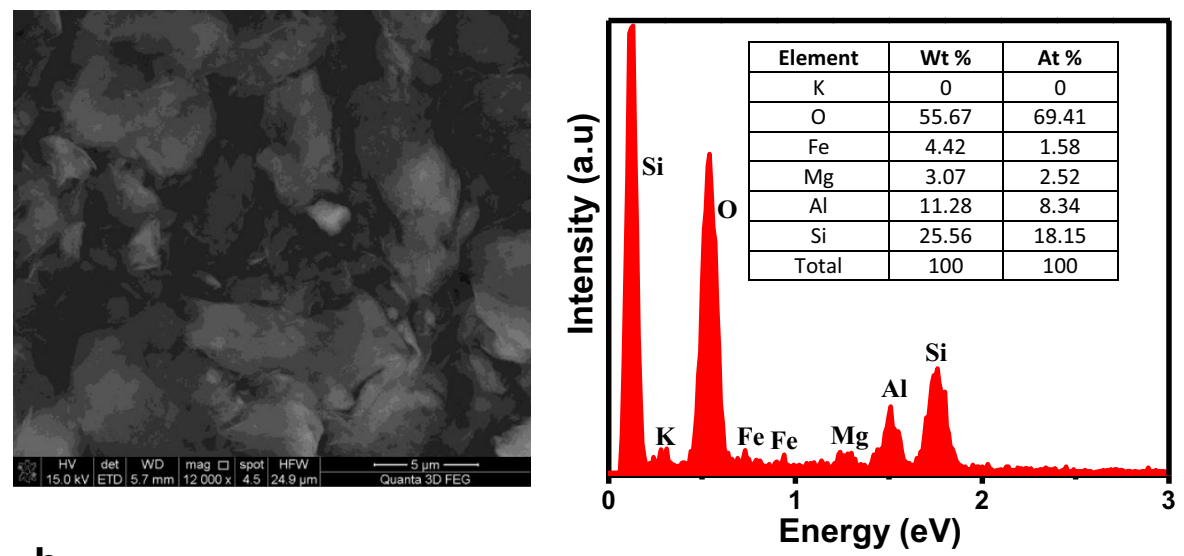

b
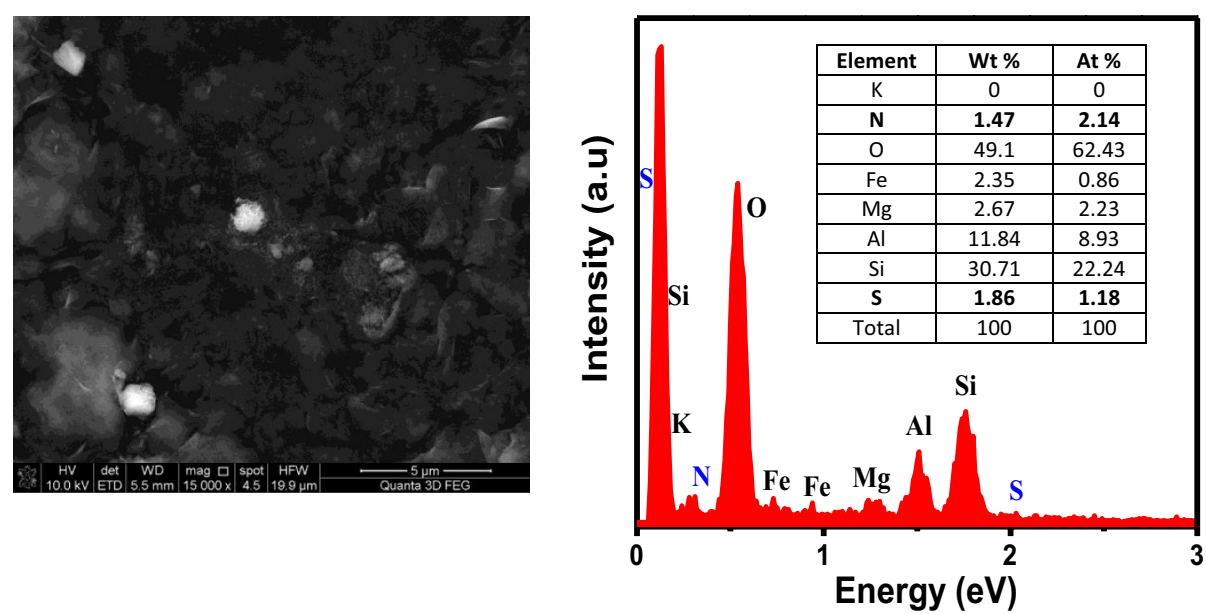

Fig. 7 FE-SEM with EDX of $\mathbf{a}$ fresh Fe(III)-Mt and $\mathbf{b}$ oxidized/spent Fe(III)-Mt 
Before treat with dye

(a)
After treat with MB dye
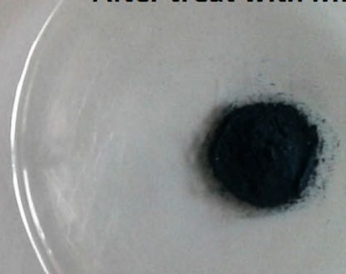

(b)

Fig. 8 Photographs showing the color of Fe(III)-Mt before (a) and after (b) interacting with $0.025 \mathrm{mM}$ MB dye solution at $\mathrm{pH}$ 7. The spent clay mineral was washed thoroughly

\section{Separation of spent Fe(III)-Mt from degraded MB dye solution}

After the dye adsorption, the spent Fe(III)-Mt settled down at the bottom within $15 \mathrm{~min}$. Then the dispersed spent Fe(III)-Mt was removed using centrifugation process. Fe(III)-Mt was completely recovered (100\%) from degraded MB dye solution as shown in Fig. 8a. At the end, we got a clear solution which is free from spent Fe(III)-Mt clay mineral.

The major disadvantage of physical methods is that the dye molecules will be transferred to another phase rather than destroyed. Additionally, biological degradation of organic contaminants suffers from low degradation efficiency, high cost and rigorous degradation conditions. Furthermore, the disposal of chemicals containing sludge at the end of degradation also entails complicated post treatment processes (Mao et al. 2014).

Graphite powder and carbon nanotubes have been used for the removal of organic dyes from aqueous wastewater; however these adsorbents usually suffer from difficulties in the separation and regeneration processes. Furthermore activated carbon was used in the removal of dyes and pigments, but the main disadvantage is activated carbon regeneration which typically involves drying at elevated temperature (He et al. 2013). Therefore, it is indispensable and emergent to explore the new reductant/adsorbent for the dye removal which could be completely separated from the degraded solution easily. Accordingly, we have successfully achieved the complete (100\%) separation of spent $\mathrm{Fe}(\mathrm{III})-\mathrm{Mt}$ from the degraded MB dye solution by centrifugation. From the experimental results, it was shown that the separation of Fe(III)-Mt from aqueous solution could be efficient, facile and reliable. Nevertheless, Fe(III)-Mt was a suitable reductant for the adsorption of dye molecules from aqueous solution with high efficiency, low cost and environmental friendliness.

\section{Comparison with other adsorbents/reductants}

Zhang et al. has described the application of porous $\mathrm{Co}_{3} \mathrm{O}_{4}$ nanorods-reduced graphene (PCNG) oxide hybrid materials for the catalytic oxidation of MB dye. PCNG showed 97\% degradation after $25 \mathrm{~min}$ in the presence of $\mathrm{H}_{2} \mathrm{O}_{2}$. However there was no degradation without PCNG or $\mathrm{H}_{2} \mathrm{O}_{2}$ (Zhang et al. 2013). Furthermore, Fe doped $\mathrm{ZnS}$ 
nanoparticles (Chauhan et al. 2013) and ferrite bismuth nanoparticles (Soltani and Entezari 2013) exhibited good photocatalytic activity of MB dye but only under visible light irradiation. $\mathrm{CoFe}_{2} \mathrm{O}_{4}$ /activated carbon nanocomposites have shown 99\% MB adsorption in $50 \mathrm{~min}$ (Xu et al. 2014). Au-tipped CdSe nanorod clusters are also used as photo catalysts for $\mathrm{MB}$ reduction via multiple electron reduction under aerobic conditions (Li et al. 2014). The main drawbacks of afore mentioned are: the reductants/adsorbents have shown incomplete reduction, time consumption is more, effectiveness only in presence of co-catalyst or additives and rapid reduction was only under visible light irradiation conditions.

More importantly, a number of nanoparticles such as $\mathrm{Au}, \mathrm{Ag}, \mathrm{Pd}$ and $\mathrm{Pt}$ have been extensively used for the degradation of dyes. However, these metal nanoparticles exhibit certain limitations including limited availability, high cost and generation of ill effects such as skin allergy, eye irritation etc. Hence metal nanoparticles have considerably faded its importance for dye degradation processes (Vinothkannan et al. 2015). Hence it is essential to propose a suitable material which acts both as reductant and adsorbent for field applications, especially to treat water and soil. We believe that $\mathrm{Fe}(\mathrm{III})-\mathrm{Mt}$ could be the efficient, facile and reliable reductant/adsorbent for the remediation of dyes from aqueous solution.

\section{Conclusion}

In this work, we have reported Fe(III)-Mt as an effective reductant cum adsorbent for removal of $\mathrm{MB}$ dye solution from aqueous solution through adsorption process under ambient conditions. The removal of $\mathrm{MB}$ dye from aqueous solution can be achieved rapidly through adsorption process by $\mathrm{Fe}(\mathrm{III})-\mathrm{Mt}$ at solid-liquid ratio, different $\mathrm{pH}$ and temperature. The removal of $\mathrm{MB}$ dye concentration was estimated from its optical density at $\lambda_{\max }=665 \mathrm{~nm}$ using UV-Vis spectrophotometer. The decrease in MB dye concentration due to reaction between $\mathrm{Fe}(\mathrm{III})-\mathrm{Mt}$ was expressed here in terms of $\%$ reduction as a function of time. In general the dye removal by Fe(III)-Mt is a rapid process, especially under stoichiometric conditions. The dye removal was rapid at basic $\mathrm{pH}$ and increases with temperature up to $40{ }^{\circ} \mathrm{C}$. A complete reduction (100\%) occurred in about $7 \mathrm{~min}$ at $\mathrm{pH} 7$ and 10, while at $\mathrm{pH} 3$, in about $10 \mathrm{~min}$. The time taken for complete reduction at 0,30 and $40{ }^{\circ} \mathrm{C}$ are 10,7 and 5 min respectively. The experimental results of $\mathrm{MB}$ dye removal from $\mathrm{Fe}(\mathrm{III})-\mathrm{Mt}$ followed the pseudo first order kinetics. The adsorption of the degraded MB dye on spent clay mineral was confirmed from FESEM/ EDAX analysis. More importantly, Fe(III)-Mt could be separated and retrieved easily after the reaction by centrifugation from the degraded MB dye solution. The enhanced removal efficiency makes $\mathrm{Fe}(\mathrm{III})-\mathrm{Mt}$ clay mineral a promising adsorbent/reductant for environmental remediation of cationic pollutants and could be applied in the purification of drinking water and large scale of industrial wastewater.

\footnotetext{
Author details

${ }^{1}$ Department of Industrial Chemistry, Kuvempu University, Shankaraghatta, Shimoga 577451 , India. ${ }^{2}$ Frontier Research Center for Post-genome Science and Technology, Hokkaido University, Sapporo 0010021, Japan. ${ }^{3}$ Department of Industrial Chemistry, Sir. M.V. Govt. Science College, Bommanakatte, Bhadravathi 577 302, India.
}

\section{Acknowledgements}

The lead author M. Vinuth wishes to thank Mr. K. Chandrasekhar for XRD analysis and also thank M. Nibin Joy, K.C. Anjaneya, G.P. Nayaka and S. Yallappa for their help during this research work. 


\section{Authors' contributions}

H.S. Bhojya naik sir guided this work very carefully with good suggestions, M.M. Mahadevaswamy helped during XRD analysis, M.C. Prabhakara gives fruitful ideas regarding adsorption and importance of clay minerals.

\section{Competing interests}

The authors declare that they have no competing interests.

Received: 21 May 2016 Accepted: 21 September 2016

Published online: 28 February 2017

\section{References}

Bigi, F., Conforti, M. L., \& Sarotori, G. (2000). Trialkylamine controlled phenol-formaldehyde reaction over clay catalysts: selective and environmentally benign synthesis of salicylic aldehydes. Tetrahedron, 56, 2709-2712.

Brigatti, M. F., Lugli, C., Cibin, G., Marcelli, A., Giuli, G., Paris, E., et al. (2000). Reduction and sorption of chromium by Fe(II)-bearing phyllosilicates: chemical treatments and X-ray absorption spectroscopy (XAS) studies. Clays and Clay Minerals, 2, 272-281.

Cenens, J., \& Schoonheydt, R. A. (1988). Tryptophan photo-oxidation by clay-adsorbed sensitizers. Clay Minerals, 23, 205-212.

Chauhan, R., Kumar, A., \& Chaudhary, R. P. (2013). Photocatalytic degradation of methylene blue with Fe doped ZnS nanoparticles. Spectrochimica Acta Part A Molecular and Biomolecular Spectroscopy, 113, 250-256.

Chen, D., Du, G., Zhu, Q., \& Zhou, F. (2014). Synthesis and characterization of TiO, pillared montmorillonites: Application for methylene blue degradation. Journal of Colloid and Interface Science, 409, 151-157.

Chowdhury, P. R., \& Bhattacharyya, K. G. (2015). Ni/Ti layered double hydroxide: synthesis, characterization and application as a photocatalyst for visible light degradation of aqueous methylene blue. Dalton Transactions. doi:10.1039/ c5dt00257e.

Dutta, K., Mukhopadhyay, S., Bhattacharjee, S., \& Chaudhuri, B. (2001). Chemical oxidation of methylene blue using a Fenton-like reaction. Journal of Hazardous Materials, 84, 57-71.

Ghorai, S., Sarkar, A., Raoufi, M., Panda, B. A., Schoonherr, H., \& Pal, S. (2014). Enhanced removal of methylene blue and methyl violet dyes from aqueous solution using a nanocomposite of hydrolyzed polyacrylamide grafted xanthan gum and incorporated nanosilica. ACS Applied Materials Interfaces, 6, 4766-4777.

Grygar, T., Hradil, D., Bezdicka, P., Dousova, B., Capek, L., \& Schneeweiss, O. (2007). Fe(III)-modified montmorillonite and bentonite: Synthesis, chemical and UV-Vis spectral characterization, arsenic sorption and catalysis of oxidative dehydrogenation of propane. Clays and Clay Minerals, 2, 165-176.

He, X., Male, K. B., Nesterenko, P. N., Brabazon, D., Paull, B., \& Luong, J. H. T. (2013). Adsorption and desorption of methylene blue on porous carbon monoliths and nanocrystalline cellulose. Applied Materials Interfaces, 5, 8796-8804.

Kloprogge, J.T. (1998). Synthesis of smectites and porous pillared clay catalysts: A review. Journal of Porous Materials, 5, $5-41$.

Kozai, N., Adachi, Y., Kawamura, S., Inada, K., Kozai, T., Sato, S., et al. (2001). Characterization of Fe(II)-mont: A stimulant of buffer materials accommodating overpack corrosion product. Journal of Nuclear Science and Technology, 38, $1141-1143$

Leungo, C., Puccia, V., \& Avena, M. (2011). Arsenate adsorption and desorption kinetics on a Fe(III)-modified montmorillonite. Journal of Hazardous Materials, 2, 1713-1719.

Li, Z., Hu, Y., \& Sun, Y. (2014). Promoting photocatalytic multiple-electron reduction in aerobic solutions using Au-tipped CdSe nanorod clusters. Chemical Communications, 50, 1411-1413.

Liu, P., \& Zhang, L. (2007). Adsorption of dyes from aqueous solutions or suspensions with clay nano-adsorbents. Separation and Purification Technology, 58, 32-39.

LV, H., Shen, X., Ji, Z., Chen, K., \& Zhu, G. (2014). One-pot synthesis of PrPO 4 nanorods-reduced graphene oxide composites and their photocatalytic properties. New Journal of Chemistry, 38, 2305-2311.

Lv, T., Pan, L., Liu, X., \& Sun, Z. (2012). Enhanced photocatalytic degradation of methylene blue by ZnO-reduced graphene oxide-carbon nanotube composites synthesized via microwave-assisted reaction. Catalysis Science Technology, 2, 2297-2301.

Ma, Y. L., Xu, Z. R., Guo, T., \& You, P. (2004). Adsorption of methylene blue on Cu(II)-exchanged montmorillonite. Journal of Colloid and Interface Science, 280, 283-288.

Mahlambi, M. M., Ngila, C. J., \& Mamba, B. B. (2015). Recent developments in environmental photocatalytic degradation of organic pollutants: The case of titanium dioxide nanoparticles-A review. Journal of Nanomaterials. doi:10.1155/2015/790173.

Manjanna, J., Kozai, T., \& Sato, S. (2009). Fe (III)-montmorillonite: Basic properties and diffusion of tracers relevant to alteration of bentonite in deep geological disposal. Applied Clay Science, 43, 208-217.

Manjanna, J., Kozaki, T., Kozai, N., \& Sato, S. (2007). A new method for Fe(II)-montmorillonite preparation using Fe(II)nitrilotriacetate complex. Journal of Nuclear Science and Technology, 44, 929-932.

Mao, Z., Wu, Q., Wang, M., Yang, Y., Long, J., \& Chen, X. (2014). Tunable synthesis of $\mathrm{SiO}_{2}$-encapsulated zero-valent iron nanoparticles for degradation of organic dyes. Nanoscale Research Letters, 9, 501.

Parthasarathy, G., Choudary, B. M., Sreedhar, B., Kunwar, A. C., \& Srinivasan, R. (2003). Ferrous saponite from the Deccan Trap, India, and its application in adsorption and reduction of hexavalent chromium. American Mineralogist, 88, 983-1988.

Rafatullah, O. S., Hashim, R., \& Ahmad, A. (2010). Adsorption of methylene blue on low-cost adsorbents: A review. Journal of Hazardous Materials, 177, 70-80. 
Samaneh, S.-S., Saeed, S.-S., Nezafati, N., \& Yahya, K. (2014). Efficient removal of lead (II) ions and methylene blue from aqueous solution using chitosan/Fe-hydroxyapatite nanocomposite beads. Journal of Environmental Management, $146,481-490$

Schwarzenbach, R. P., Escher, B. I., Fenner, K., Hofstetter, T. B., Johnson, C. A., Gunten, U. V., et al. (2006). The challenge of micropollutants in aquatic systems. Science, 313, 1072-1077.

Shannon, M. A., Bohn, P.W., Elimelech, M., Georgiadis, J. G., Marinas, B. J., \& Mayes, A. M. (2008). Science and technology for water purification in the coming decades. Nature, 452, 301-310.

Shi, L.-N., Zhang, X., \& Chen, Z.-L. (2011). Removal Cr(VI) from waste water using bentonite-supported nanoscale zerovalent iron. Water Research, 45, 886-892.

Sohrabnezhad, S., Pourahmad, A., \& Radaee, E. (2009). Photocatalytic degradation of basic blue 9 by CoS nanoparticles supported on AIMCM-41 material as a catalyst. Journal of Hazardous Materials, 170, 184-190.

Soltani, T., \& Entezari, M. H. (2013). Photolysis and photocatalysis of methylene blue by ferrite bismuth nanoparticles under sunlight irradiation. Journal of Molecular Catalysis A Chemical, 377, 197-203.

Stucki, J. W. (2006). Iron redox processes in smectites. In F. Bergaya, B. K. G. Theng, \& G. Lagaly (Eds.), Handbook of clay science, Ch. 8. Amsterdam: Elsevier.

Vinoda, B. M., \& Manjanna, J. (2014). Dissolution of iron in salicylic acid and cation exchange between Fe(II)-salicylate and $\mathrm{Na}$-montmorillonite to form Fe(II)-montmorillonite. Applied Clay Science, 97, 78-83.

Vinothkannan, M., Karthikeyan, C., Gnana kumar, G., Kim, A. R., \&Yoo, D. J. (2015). One-pot green synthesis of reduced graphene oxide ( $\mathrm{RGO}) / \mathrm{Fe}_{3} \mathrm{O}_{4}$ nanocomposites and its catalytic activity toward methylene blue dye degradation. Spectrochimica Acta Part A Molecular and Biomolecular Spectroscopy, 136, 256-264.

Vinuth, M., Bhojya Naik, H. S., Chandra sekhar, K., Manjanna, J., \& Vinoda, B. M. (2015). Environmental remediation of hexavalent chromium in aqueous solution using Fe(II)-montmorillonite as reductant. Procedia Earth Planetary Science, 11 $275-283$.

Wang, Q., Tian, S., \& Ning, P. (2014). Degradation mechanism of methylene blue in a heterogeneous fenton-like reaction catalyzed by ferrocene. Industrial and Engineering Chemistry Research, 53, 643-649.

Wu, P., Li, S., Ju, L., Zhu, N., Wu, J., Li, P., et al. (2012). Mechanism of the reduction of hexavalent chromium by organomontmorillonite supported iron nanoparticles. Journal of Hazardous Materials, 219, 283-288.

Xie, Y., Yan, B., Xu, H., Chen, J., Liu, Q., Deng, Y., et al. (2014). Highly regenerable mussel-inspired Fe $\mathrm{O}_{4} @$ @polydopamine-Ag core-shell microspheres as catalyst and adsorbent for methylene blue removal. ACS Applied Materials Interfaces, 6, $8845-8852$

Xu, J., Xin, P., Gao, Y., Hong, B., Jin, H., Jin, D., et al. (2014). Magnetic properties and methylene blue adsorptive performance of $\mathrm{CoFe}_{2} \mathrm{O}_{4}$ /activated carbon nanocomposites. Materials Chemistry and Physics, 147, 915-919.

Yao, Y., Xu, F., Chen, M., Xu, Z., \& Zhu, Z. (2010). Adsorption behavior of methylene blue on carbon nanotubes. Bioresource Technology, 101, 3040-3046.

Zhang, N., Zhang, Y. H., \& Xu, Y. J. (2012). Recent progress on graphene-based photocatalysts: Current status and future perspectives. Nanoscale, 4, 5792-5813.

Zhang, Z., Hao, J., Yang, W., Lu, B., Ke, X., Zhang, B., et al. (2013). Porous Co3O4 Nanorods - Reduced Graphene Oxide with Intrinsic Peroxidase-Like Activity and Catalysis in the Degradation of Methylene Blue. ACS Appl. Mater. Interfaces, 5, 3809-3815.

\section{Submit your manuscript to a SpringerOpen ${ }^{\circ}$ journal and benefit from:}

- Convenient online submission

- Rigorous peer review

- Immediate publication on acceptance

Open access: articles freely available online

- High visibility within the field

- Retaining the copyright to your article

Submit your next manuscript at $\boldsymbol{\nabla}$ springeropen.com 